\title{
Interleukin-6 gene polymorphisms and its relation to spontaneous preterm labour among Egyptian women
}

\author{
Original Mahmoud Al-Alfy ${ }^{1}$, Haitham Torky ${ }^{3}$, Osama Azmy ${ }^{1}$,Hazem El-Hariri ${ }^{4}$, Iman zein ${ }^{5}$ \\ Article \\ ${ }^{I}$ Reproductive Health and Family Planning Research Department, National Research Centre, \\ Egypt, ${ }^{2}$ Obstetrics and Gynecology Department, Faculty of Medicine, Cairo University, Egypt, \\ ${ }^{3}$ Obstetrics and Gynecology Department, Faculty of Medicine, 6th October University, Egypt, \\ ${ }^{4}$ Community Medicine \& Epidemiology, National research center, ${ }^{5}$ Obstetrics and Gynecology \\ Department ,Faculty of Medicine ,Benisuef University, Egypt
}

\begin{abstract}
Objective: to verify the possible relationship between interleukin-6 (IL-6) promoter -174 polymorphisms and spontaneous preterm birth between 28 and 37 weeks of gestation among Egyptian women.

Methods: This is a multicenter case control study comprising 184 pregnant women between 28 and $36+6$ weeks of gestational age (GA) at termination, divided into a study group including sixty one women with established preterm labor, and another 123 pregnant women at full term represented the control group. Venous blood samples were taken for DNA extraction using QIAamp DNA Blood Mini Kit for IL-6 promoter polymorphism status.

Results: Among the preterm delivering women, $65.6 \%, 26.2 \%$ and $8.2 \%$ had $\mathrm{C} / \mathrm{C}, \mathrm{G} / \mathrm{C}$ and G/G variants, respectively. On the other hand, within the 123 women representing the control group, we found $84.6 \%, 15.4 \%$ who showed $\mathrm{C} / \mathrm{C}$ and $\mathrm{G} / \mathrm{C}$ variants. There was no single woman showing the $\mathrm{G} / \mathrm{G}$ variant. This was statistically significant $(P<0.05)$.

Conclusion: The genetic make-up of interleukin- 6 production may have a role in the etiology of preterm labour among Egyptian women of Middle Eastern ethnicity. PCR for IL-6 polymorphism could be proposed as one of the predictors for preterm labor, however, in a multi-factorial problem like preterm labor it is not the only predictor tool.
\end{abstract}

Key Words: egyptian women, gene polymorphisms, interleukin -6, preterm labor.

Received: 12 March 2017, Accepted: 3 May 2017

Corresponding Author: Tamer Fouad Taha, Reproductive Health and Family Planning Research Department, National Research Centre, Egypt Tel.: +201002595590,E-mail: tamtaha2k@yahoo.com

ISSN: 2090-7265, August 2017, Vol. 7, No. 3

\section{INTRODUCTION}

Prematurity or preterm birth (PTB) is one of the major causes of neonatal mortality and birth related morbidity without congenital anomalies or chromosomal abnormalities ${ }^{[1,2]}$. It is responsible of fifty six percent of neonatal deaths and fifty percent of neonatal neurological disability ${ }^{[3]}$. In spite of this high neonatal mortality and morbidity 5- $11 \%$ of deliveries are still premature 4 . This rate did not decrease in the past 40 years, in spite of advances in obstetric care ${ }^{[5]}$. The etiology of preterm labour is complex and multifactorial6.There is compelling evidence that both maternal and fetal genomes contribute to risk $^{[7]}$.

African-American ancestry is consistently associated with an increased risk of preterm birth even after considering the epidemiologic risk factors, such as income, education, lack of prenatal care, and other socioeconomic factors $^{[8]}$.

Expression studies of IL-6 with allelic variants of the rs1800795 polymorphism have produced different results in different tissues ${ }^{[9]}$. However, there is no strong evidence of natural selection near rs 180079510 . Activated lymphocytes and macrophages are the primary source of the biologically active glycoproteins (Interleukins). The progress in recombinant DNA technology, cell culture techniques and protein purification have led to study of the biological and biochemical properties of interleukins ${ }^{[1]}$.

Activated T lymphocytes, blood monocytes, fibroblasts and tissue macrophages secrete $26 \mathrm{kD}$ glycoprotein which is coded as Interleukin-6 (IL-6)12. Interleukin-6 activates 
the acute phase response and induces $C$ reactive protein production and terminal differentiation of B lymphocytes, therefore, it is a crucial cytokine in the response of the host to infection ${ }^{[13]}$. Amniotic fluid concentration of IL-6 increases more than that of other pro-inflammatory products in cases of intrauterine infection and preterm labor ${ }^{[14]}$. This increase in IL-6 is also seen in amniotic fluid, maternal serum and cervix in cases of preterm labor ${ }^{[15]}$. The risk of preterm labor approximately doubled in the study done by Romero and his colleagues when a single nucleotide polymorphism involved in controlling fetal inflammation (IL-6 receptor 1) and DNA variants in maternal genes encoding for proteins involved in extracellular matrix metabolism occurred ${ }^{[16]}$.

Many human cytokine genes polymorphisms have been described $^{[17]}$. Polymorphisms are normal allelic variation present within the regulatory region of cytokine genes. Increased severity of certain autoimmune diseases and increased susceptibility to certain infections are associated with specific polymorphisms ${ }^{[18]}$. Polymorphism in the promoter region of IL-6 (At position 174) on chromosome 7 is associated with the production of IL-6. Decrease in the promoter activity is due to substitution of cytosine (C) for guanine $(\mathrm{G})$ at this position. Lower production of IL-6 is present in individuals who have cytosine at both positions (homozygous $\mathrm{C} / \mathrm{C}$ ) as compared to individuals who have guanine at both positions (homozygous $\mathrm{G} / \mathrm{G}$ ) or at one position (heterozygous $\mathrm{G} / \mathrm{C}$ ) who have normal IL-6 production $^{[19]}$.

The aim of this study was to verify the possible relationship between IL-6 promoter -174 polymorphisms and spontaneous preterm birth between 28 and $36+6$ weeks of gestation in a trial to find a good predictor to preterm birth which is a major problem in Egypt.

\section{PATIENTS AND METHODS}

In this multicenter case control study, two hundred and thirty four were recruited all of them had Middle Eastern ethnicity and Arabic speaking language. Inclusion criteria included healthy women with singleton living fetus, while, exclusion criteria were women with medical or obstetric problems other than preterm labor, those taking any form of medications except multi-vitamins, any form of infection, fever, multiple pregnancies or a fetus with congenital anomalies. One hundred and eighty four women met the inclusion criteria were enrolled in the study. Fifty women were excluded due to premature rupture of the membranes (34/50), evident vaginal infection (11/50) by clinical and high vaginal swab results, three women had urinary tract infection (3/50) by mid stream urine test and two women had babies with major congenital malformation (2/50). The cases were recruited from the antenatal care clinic and casualty unit of Obstetrics and Gynecology department, Kasr El Eini hospital, Cairo University, Benisuef university hospital and the Obstetrics and Gynecology Department 6th October University as well as the antenatal clinic of Reproductive Health and Family Planning department, Medical Research Centre of Excellence, National Research Centre, Cairo. This was carried out during the period from October 2011 to May 2012. Informed written consents of all participants were taken. The Ethical Committees of the National research Centre, Kasr El Eini University Hospital and $6^{\text {th }}$ October University Hospital also endorsed their approval for the study. All women within the study group were pregnant between $28-36^{6+}$ weeks, while controls were pregnant 37 weeks or more.

The study group included 61 pregnant women with established preterm labor confirmed by regular uterine contractions (3- 5 contractions/10minutes each lasted for 45- 60 seconds) increasing strength, frequency and duration associated with cervical changes (cervical dilation $>3 \mathrm{~cm}$ ). Contractions were monitored using continuous cardiotocography. The control group represented the one hundred and twenty three women who were at full-term $\left(>37^{0+}\right.$ weeks) with no symptoms or signs of labor.

All women were subjected to detailed history taking including nutritional history, educational history \& information about the socio-economic status. Examination by sterile speculum prior to digital vaginal examination to rule out rupture of membranes and high vaginal swabs were taken. Two-dimensional ultrasound was performed for fetal biometry, placental localization and detection of possible gross fetal anomalies. Urine samples were taken for analysis. Venous blood samples were taken for DNA extraction using QIAamp DNA Blood Mini Kit (Qiagen, Valencia, CA, USA) according to the manufacturer's "Blood and Body Fluid Spin Protocol". Real time PCR was used to determine IL-6 promoter polymorphism status using the following primers and probes;

\section{5'- GACGACCTAAGCTGCACTTTTC-3', \\ 5'- GGGCTGAT-TGGAAACCTTATTAAGATTG-3', \\ 5'- CTTTAGCAT(C) GCAAGAC-3', \\ 5'- CTTTAGCAT (G) GCAAGAC-3'.}

\section{Statistical analysis}

Data was analysed using IBM SPSS Advanced Statistics version 20.0. Numerical data were expressed as mean and standard deviation and range. Qualitative data were expressed as frequency and percentage. Fisher's exact test was used to examine the relation between qualitative variables. For quantitative data, comparison between two groups was done using independent sample t-test. $P$ value $<0.05$ was considered significant. 


\section{RESULTS}

In this study the mean age of the case and control groups is $27.8 \pm 3.7$ and $28.0 \pm 3.8$, respectively (ranging from 21.0 to 37.0 years in both). Moreover, the mean gestational age of the case groups is $33.3 \pm 1.6$ (ranging from 28.0 to $36.0+6$ ), while that of the control group is $38.8 \pm 1.4$ (ranging from 37.0 to 42.0 ).

Among the preterm delivering women, there were 40 women $(65.6 \%)$ with $\mathrm{C} / \mathrm{C}$ variant, 16 women $(26.2 \%)$ with $\mathrm{G} / \mathrm{C}$ variant and five women $(8.2 \%)$ with $\mathrm{G} / \mathrm{G}$ variants. On the other hand, within the one hundred and twenty three women representing the control group, there were 104 women $(84.6 \%)$ who showed $\mathrm{C} / \mathrm{C}$ variant and 19 women $(15.4 \%)$ with $\mathrm{G} / \mathrm{C}$ variant, while no single woman showing the $\mathrm{G} / \mathrm{G}$ variant. This difference between the two groups was statistically significant ( $P=0.001$ ) (Table 1$)$. The odds ratio for $\mathrm{C} / \mathrm{C}$ genotype was $0.35(95 \%$ confidence interval $=0.17-0.79)$

Sub-analysis of the groups according to gestational age at delivery among case group was $33.9 \pm 1.0,32.8$ \pm 1.6 and $29.2 \pm 0.8$ for $\mathrm{C} / \mathrm{C}, \mathrm{G} / \mathrm{C}$ and $\mathrm{G} / \mathrm{G}$ respectively with significant difference for $\mathrm{G} / \mathrm{G}$ than both $\mathrm{C} / \mathrm{C}$ and $\mathrm{G} / \mathrm{C}$ that showed no significant difference between them (Figure 1), while gestational age at pregnancy termination among control group was $38.8 \pm 1.3$ and 38.4 \pm 1.7 for $\mathrm{C} / \mathrm{C}$ and $\mathrm{G} / \mathrm{C}$ respectively with no significant difference between them.

Table 1: Comparison between cases and controls as regard interleukin-6 gene polymorphisms

\begin{tabular}{lllll}
\hline & Genotype & Study group & Control group & $P$ \\
\cline { 2 - 5 } & & & & \\
& & & & \\
& & $65.6 \%$ & $86.2 \%$ & \\
& & $(40 / 61)$ & $(106 / 123)$ & \\
IL-6 gene promoter- & 147 & & $13.8 \%$ & 0.001 \\
polymorphisms & G/C & $26.2 \%$ & $(17 / 123)$ & \\
& & $(16 / 61)$ & $0 \%$ & \\
& G/G & $8.2 \%$ & $(0 / 123)$ & \\
\hline
\end{tabular}

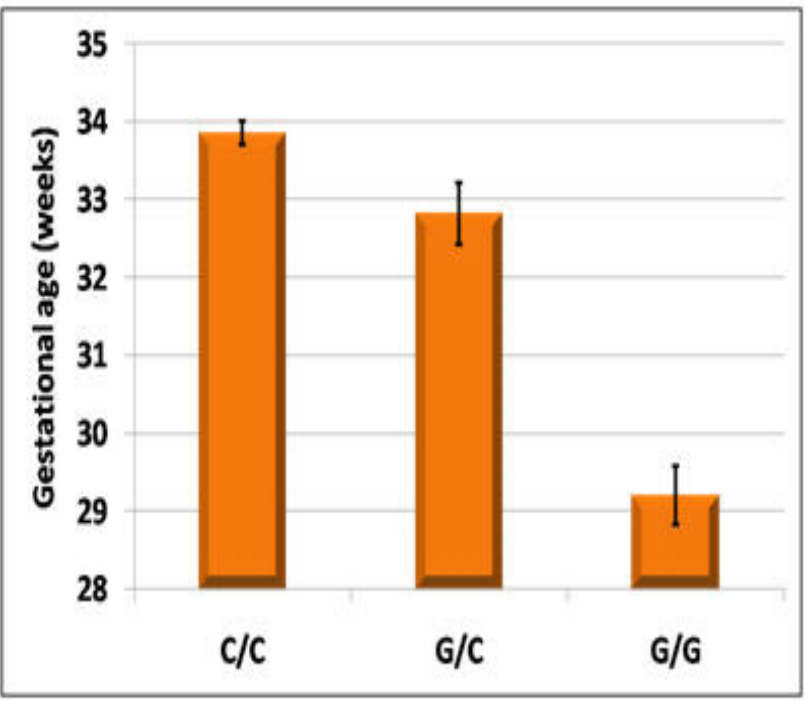

Fig. 1: Comparison between interleukin-6 gene polymorphisms as regard gestational age at delivery case group, C: cytosine, G: guanine.

\section{DISCUSSION}

IL-6 is a critical element of the host response to infection and genetic variation in its production may influence the nature and degree of inflammatory activity. Furthermore, infections or inflammatory diseases are also influenced by the genetic regulation of IL-6 production. Cox and colleagues have demonstrated that lower frequency of acute rejection in renal transplant is seen in patients who have genetic predisposition towards lower production of IL-6 20 .

Our results have shown that women with $\mathrm{G} / \mathrm{G}$ variant of IL- 6 gene have almost doubled the risk for preterm birth (OR 1.5, 95\% CI 0.593.83-). On the other hand, women carrying the $\mathrm{C} / \mathrm{C}$ variant are less likely to deliver before term (OR $0.43,95 \%$ CI $0.21-0.89$ ). We believe that the $\mathrm{C} / \mathrm{C}$ variant of IL- 6 gene is a protective one against spontaneous preterm delivery. In a previous study by Simhan and his team in (2003), they studied a group of Afro-American and white women. They revealed that 
the IL-6 - 174 allelic variant $\mathrm{C} / \mathrm{C}$ is significantly less frequent among women with spontaneous preterm birth less than 34 weeks $^{[21]}$. This was endorsed by the results of the meta-analysis carried out by $\mathrm{Wu}$ et al. (2013), who studied preterm labor phenotype and single nucleotide polymorphism (SNP) rs1800795 in both mothers and babies separately then stratified the results by population. They concluded that IL-6 SNP rs1800795 genotype $\mathrm{C} / \mathrm{C}$ was protective against preterm labor in women of European descent ${ }^{[22]}$.

We also noted that primigravid women whether carrying the homozygous or the heterozygous form of the $\mathrm{G}$ variant are more likely to have give birth at less than 34 weeks gestation than their counterparts. This may partly be explained by the better antenatal care and medical steps taken to avoid preterm delivery and the medication received as a result of the previous preterm birth. Moreover, epigenetic and other environmental factors may play a role in affecting the expression and action of IL-6 gene. This was shown in our study as we noticed that most cases of preterm birth lived in industrial areas which have high rates of pollution suggesting a possible role of pollution in this genetic polymorphism. We also noticed that most cases of preterm labor were among women with lower level of education, the latter may have been a cause for delayed seeking of medical advice.

\section{CONCLUSION}

The genetic make-up of interleukin-6 production may have a role in the etiology of preterm labour among Egyptian women. PCR for IL-6 polymorphism could be proposed as one of the predictors for preterm labor, however, in a multi-factorial problem like preterm labor it is not the only predictor tool. The level of education also plays a role in early detection of preterm labor among Egyptian women of Middle Eastern ethnicity which may increase the chances of success of tocolytic therapy in early cases. Accurate tools for detection of preterm labor will assist in the development of targeted treatments to alleviate this major public health problem.

\section{CONFLICTS OF INTEREST}

There are no conflicts of interest.

\section{REFERENCES}

1. Hamilton BE, Hoyert DL, Martin JA, Strobino DM, Guyer B. Annual summary of vital statistics: 2010 2011. Pediatrics. 2013; 131:548-558.
2. Mathew T, MacDorman M. Infant Mortality Statistics from the 2003 Period Linked Birth/Infant Death Data Set. Nati Vital Stat Report. 2006; 54:1 -9.

3. Shenan AH. Recent developments in obstetrics. BMJ.2003; 13: 604- 608.

4. Andrews WW1, Goldenberg RL, Mercer B, Iams J, Meis P, Moawad A, Das A, Vandorsten JP, Caritis SN, Thurnau G, Miodovnik M, Roberts J, McNellis D.The Preterm Prediction Study: association of secondtrimester genitourinary chlamydia infection with subsequent spontaneous preterm birth. Am J Obstet Gynecol. 2000; 183: 662-668.

5. Goldenberg RL. The management of preterm labor. Obstet Gynecol, 2002; 100: 10201037-.

6. Haataja R, Karjalainen MK, Luukkonen A, Teramo K, Puttonen H, Ojaniemi M, Varilo T, Chaudhari BP, Plunkett J, Murray JC, McCarroll SA, Peltonen L, Muglia LJ, Palotie A, Hallman M. Mapping a new spontaneous preterm birth susceptibility gene, IGF1R, using linkage, haplotype sharing, and association analysis. PLoS Genet. 2011;7: e1001293. doi: 10.1371/journal.pgen.1001293.

7. Manuck TA, Lai Y, Meis PJ, Sibai B, Spong CY, Rouse DJ, Iams JD, Caritis SN, O'Sullivan MJ, Wapner RJ, Mercer B, Ramin SM, Peaceman AM. Admixture mapping to identify spontaneous preterm birth susceptibility loci in African Americans. Obstet Gynecol. 2011;117:1078-1084.

8. Tsai H-J, Hong X, Chen J, Liu X, Pearson C, Ortiz K, Hirsch E, Heffner L, Weeks DE, Zuckerman B, Wang $\mathrm{X}$. Role of African ancestry and gene-environment interactions in predicting preterm birth.Obstet Gynecol. 2011;118:1081-1089.

9. Smith AJP, Humphries SE. Cytokine and cytokine receptor gene polymorphisms and their functionality. Cytokine Growth Factor Rev.2009;20: 43-59.

10. Wilfred Wu, Erin AS, Gregory JS, W Scott W, Sean E, Tracy AM, Jinchuan X, Michael WV, Lynn B. Effect of interleukin- 6 polymorphism on risk of preterm birth within population strata: a meta-analysis. BMC Genet. 2013; 14: PMC3639799. doi: 10.1186-2156-1471/ 30-14.

11. Acs G, Gerok W, et al. Regulation of interleukin-6 expression in cultured human blood monocytes and monocyte-derived macrophages. Blood 1988; $72: 1134-1140$

12. Papanicolaou DA, Wilder RL, Manolagas SC, Chrousos GP. The pathophysiologic roles of 
interleukin-6 in human disease. Ann Intern Med 1998;128: 127- 137.

13. El-Bastawissi AY, Williams MA, Riley DE, Hitti $\mathrm{J}$, Krieger JN. Amniotic fluid interleukin-6 and preterm delivery: a review. Obstet Gynecol. 2000; 95:1056- 1064

14. Weiyuan Z, Li W. Study of interleukin-6 and tumor necrosis factor alpha levels in maternal serum and amniotic fluid of patients with premature rupture of membranes. J Perinat Med 1998;26:491 -494.

15. Romero R, Avila C, Santhanam U, Sehgal PB. Amniotic fluid interleukin 6 in preterm labor: association with infection. J Clin Invest 1990;85:1392- 1400

16. Romero R1, Velez Edwards DR, Kusanovic JP, Hassan SS, Mazaki-Tovi S, Vaisbuch E, Kim CJ, Chaiworapongsa T, Pearce BD, Friel LA, Bartlett J, Anant MK, Salisbury BA, Vovis GF, Lee MS, Gomez R, Behnke E, Oyarzun E, Tromp G, Williams SM, Menon R. Identification of fetal and maternal single nucleotide polymorphisms in candidate genes that predispose to spontaneous preterm labor with intact membranes. Am J Obstet Gynecol. 2010;202(5); 431- 434.

17. Fishman D, Faulds G, Jeffery R, Mohamed-Ali V, Yudkin JS, Humphries S, Woo P. The effect of novel polymorphisms in the interleukin-6 (IL-6) gene on IL-6 transcription and plasma IL-6 levels, and an association with systemic-onset juvenile chronic arthritis. J Clin Invest. 1998;102:1369- 1376.

18. Van Deventer SJ. Cytokine and cytokine receptor polymorphisms in infectious disease. Intensive Care Med. 2000;26: 98- 102.

19. Hutchinson IV, Pravica V, Perrey C, Sinnott P. Cytokine gene polymorphisms and relevance to forms of rejection. Transplant Proc.1999; 31:734 -736.

20. Cox ED, Hoffmann SC, Di Mercurio BS, Wesley RA, Harlan DM, Kirk AD, Blair PJ. Cytokine polymorphic analyses indicate ethnic differences in the allelic distribution of interleukin-2 and interleukin-6. Transplantation. 2001; 72:720- 726.

21. Simhan HN, Krohn MA, Roberts JM, Zeevi A, Caritis SN. Interleukin-6 promoter-174 polymorphism and spontaneous preterm birth. Am J Obstet Gynecol. 2003;189:915-918.

22. Wu W, Clark EA, Stoddard GJ, Watkins WS, Esplin MS, Manuck TA, Xing J, Varner MW, Jorde LB. Effect of interleukin-6 polymorphism on risk of preterm birth within population strata: a meta-analysis. BMC Genet. 2013; 25:14 -30. 